reference to my paper to the Ropal Society, already quoted, and to my work on Tuberculosis, $2 d$ Edition, p. xii., Introduction, and p. 68 of the work itself. In that work, I was espccially relating the effects of yancreatic emulsion as used at the Royal Hospital for Diseases of the Chest in the treatment of consumption, and pancreatine was only mentioned in passing. Since that work was published, I lave used pancreatine extensively in the treatment of different forms of dyspepsia and wasting fever from mal-assimilation. When properly prepared, it is certainly an extremely raluable remedy. It far exceeds pepsine in its results, because it assists in the digestion of carbohydrates, hydrocarbons and albuminoids. When required more especially for digestion of albuminoids and carbohydrates, it should be given directly after food; where it is the hydrocarbons which especially require its use, it should be giren one hour after the meal; when giren to assist the digestion of cod-liver oil, it should be mixed with the dose of oil at the time of administration. (See British Medical Journal, Feb. 8, 1868.) In my practice, I always use Sarory \& Moore's pancreatine powder, and I have no confidence in any other form. "All attempts to isolate the several properties of the pancreas have failed, no one of such products having been found to possess in perfection the property of acting upon fat, \&c., in the manner described in this paper as peculiar to the pancreas. By the term 'pancreatine,' then, I desire to represent the entire property of the pancreas, extracted in a convenient form for keeping, for experiment, and for administration as a remedial agent." - (Proceedings of Royal Society, No. 97, already referred to.)

\title{
RUPTURE OF THE RIGHT AURICLE OF THE HEART FROM SUDDEN COMPRESSION OF THE THORAX.
}

By Robert AMory, M.D., Brobikline.

LAST May I was called, between the hours of 3 and 4 in the morning, to a railroad station in Longwood. On my arrival, the only history to be obtained was as follows: A man, about 23 years of age, was trying to "couple" a passenger car, having a Miller platform, to another car in front with a common platform. In doing this, he stood between the two cars, facing the forward one, with the pin held up in one hand. The engine backed the forward car on to the hinder one, thus compressing the thorax of the man between them; but not so forcibly, as was afterward ascertained by a post-mortem, as to break any bones either in front or back of the thorax. Judging from the circumstances, the platform of the forward car was on a level just below that of the diaphragm, whilst the level of the other platform behind must have been at least four inches higher, bringing the compression behind at the scapular region. I arrived about twenty minutes after the accident, and found the body 
of the man lying upon its back on the floor, in a state of commencing post-mortem rigidity. This condition of rigidity $I$ reserve for future consideration, and will relate the facts of the autopsy, which was performed by Dr. Trull and myself at 10 o'clock the same morning, six and a half hours after the accident.

Complete muscular rigidity, the right arm extended upwards in a state of semi-flexion at the elbow-joint, the left arm very slightly flexed at the elbow-joint, but hanging down by the side. No marks of external bruise or abrasion upon any part of the skin. No appearance of fracture of any bone. After making an incision along the median line over the sternum and exposing the bones of the thorax, we cautiously removed the sternum by cutting the costal cartilages, and the anterior mediastinum was exposed to view. The external surface of the pericardium was whitened and corered here and there with white flocculent or fibrinous particles. Its appearance was rough. On opening the pericardial sac, about a pint of clear serum poured out, which was soon followed by reddened serum, and afterwards by dark thick blood. This latter seemed to have been present in different strata, the upper being thin serum, and the lower thick blood and a few coagula. After cleaning out the interior of the sac, the dark blood was seen to pour out from an opening on the anterior aspect of the right auricle. After the auricle had been emptied of blood, we examined this opening, and found that in the inner layers of tissue the opening was wider than in the outer layers. A careful examination of the cavities of the heart showed no appearance of valvular discase or fatty degeneration.

I assume that the sudden and severe compression of the thoracic walls was transmitted to the thoracic viscera at a time when the right auricle was full of blood pouring in from the renæ cavæ, and consequently when its walls were thinnest and weakest; the blood not being emptied fast enough caused a rupture of the auricular sac from the sudden compression. As the court of inquest were waiting for the result of the autopsy, we had no time for further examination, the rupture of the auricle being sufficient cause of death. From our hasty examination, no other lesion of the thoracic viscera was determined.

Prevention of Tormenting of Horses, ETC., BX Flies.-M. Lochard, a veterinary surgeon, describes a simple and economical means of preventing the sutfering which is induced in horses and other animals by the persecution of flies, and which our provincial readers will probably be induced to try. It consists in painting with a pencil the insides of the ears, or other parts liable to be bitten, with a few drops of empyreumatic juniper oil (huile de cade). Insects will not approach the parts so painted, and the cost of the oil is trifling.-Journal de Connaissances Méd.; Cincinnati Clinic. 